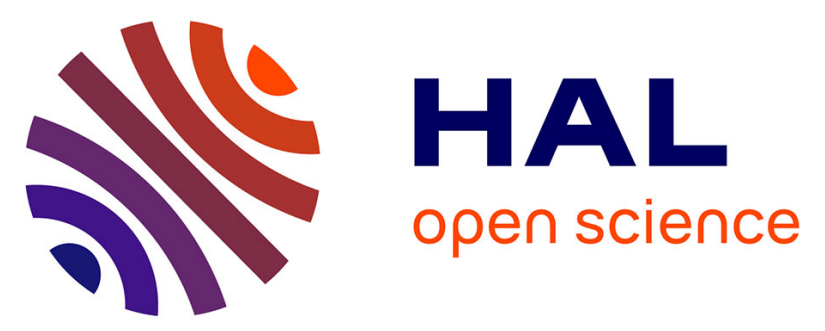

\title{
A Suspended Silicon Terahertz platform with low loss waveguide and high Q Photonic Crystal cavities
}

Elias Akiki, Mattias Verstuyft, Guillaume Ducournau, Benjamin Walter, Estelle Mairiaux, Marc Faucher, Jean-Francois Lampin, Bart Kuyken, Mathias Vanwolleghem

\section{To cite this version:}

Elias Akiki, Mattias Verstuyft, Guillaume Ducournau, Benjamin Walter, Estelle Mairiaux, et al.. A Suspended Silicon Terahertz platform with low loss waveguide and high Q Photonic Crystal cavities. 2019 44th International Conference on Infrared, Millimeter, and Terahertz Waves (IRMMW-THz), Sep 2019, Paris, France. pp.1-2, 10.1109/IRMMW-THz.2019.8873957 . hal-03100266

\section{HAL Id: hal-03100266 https://hal.science/hal-03100266}

Submitted on 8 Jan 2021

HAL is a multi-disciplinary open access archive for the deposit and dissemination of scientific research documents, whether they are published or not. The documents may come from teaching and research institutions in France or abroad, or from public or private research centers.
L'archive ouverte pluridisciplinaire HAL, est destinée au dépôt et à la diffusion de documents scientifiques de niveau recherche, publiés ou non, émanant des établissements d'enseignement et de recherche français ou étrangers, des laboratoires publics ou privés. 


\title{
A Suspended Silicon Terahertz platform with low loss waveguide and high Q Photonic Crystal cavities
}

\author{
Elias Akiki ${ }^{1}$, Mattias Verstuyft ${ }^{2}$, Guillaume Ducournau ${ }^{1}$, Benjamin Walter $^{3}$, Estelle Mairiaux ${ }^{3}$, Marc \\ Faucher $^{1}$, Jean-François Lampin ${ }^{1}$, Bart Kuyken ${ }^{2}$, Mathias Vanwolleghem ${ }^{1}$ \\ 1. Univ. Lille, CNRS, Centrale Lille, ISEN, Univ. Valenciennes, UMR 8520 - IEMN, F-59000 Lille, France \\ 2. Photonics Research Group, Department of Information Technology, Ghent University-imec, Ghent, Belgium
}

\section{Vmicro SAS, Villeneuve d'Ascq, France}

\begin{abstract}
A high Q optical resonator and ultra-low losses of a silicon suspended waveguide, are experimentally measured and presented, in order to demonstrate the working of a designed photoacoustic terahertz gas sensor presented in our previous work.
\end{abstract}

\section{INTRODUCTION}

$\mathrm{T}$ ERAHERTZ waves have shown many interest in many applications such as gas sensing and spectroscopic techniques... But the detection and the generation of these type of waves is still complicated and challenging. Photoacoustic technique[1] is one solution for this problem, so it allows to transform the terahertz signal hard to detect, in an acoustical signal that could be heard. An integrated sensor that consist of triple resonator system (optical - acoustical and mechanical resonator) is designed and theoretically demonstrated by our colleagues. These resonators allow to enhance the low signals in order to detect low concentration of polar gas molecules. A terahertz modulated light is guided in a Silicon suspended waveguide, then confined and resonant in a high Q photonic crystal optical cavity at absorption frequency of targeted gas. The gas present in the medium absorb the enhanced modulated light. The modulated excitation relaxation process of molecules, create vibrations at $\mathrm{THz}$ light modulation frequency. This optical cavity has the shape of a cylindrical acoustic cavity that enhance the acoustical signal generated by the vibrations, and a microphone formed by an $\mathrm{Si}_{3} \mathrm{~N}_{4}$ membrane on the top of this cylinder detect these vibrations.

In this work we present experimental high Q measurement of the optical resonator and low losses of the silicon suspended waveguide, that form the optical part of this sensor. However, the acousto-mechanical part and the photoacoustic work of this sensor are under test. A silicon suspended waveguide, form the guiding channel of the terahertz waves. The absence of substrate in this waveguide and the use of high resistivity silicon to form it core, helps to achieve a very low loss waveguide. The core of this ultra-low loss waveguide is etched to form an optical terahertz cavity with a high $\mathrm{Q}$ factor.

\section{SILICON WAVEGUIDE DESIGN AND LOSS EXTRACTION}

The designed Silicon guiding channel has a width(w) and thickness (T) of 210x90 $\mu \mathrm{m}$. These defined width and thickness allow the propagation of four modes, $E_{x}^{11}, E_{y}^{11}, E_{x}^{21}, E_{y}^{21}$. The fundamental mode $E_{x}^{11}$ highly confined in the Silicon channel $(89 \%)$, is represented in Fig.1a where the transverse component of the electric field $\vec{E}$ is in the X direction. Another single mode waveguide is also designed. Lower dimensions $(150 \times 70 \mu \mathrm{m})$, increase the cut-off frequencies of higher order mode, but this also reduce the confinement factor (83\%) (Fig.1b). Using this waveguide for applications that consist a high confinement factor of the electric field such as high Q optical cavity, make the $210 \times 90 \mu \mathrm{m}$ device interesting to fabricate and measure experimentally.

The guiding channel is formed by one process, DRIE etching of 90 microns thick high-Res SOI wafer, that correspond exactly to the thickness of the guiding channel, which has a width of $210 \mu \mathrm{m}$. These defined dimensions of the Si core, allow to highly confine and guide terahertz optical modes for frequencies beyond $0.5 \mathrm{THz}$, due to the high refractive index contrast between core-cladding materials (nsi/nair).
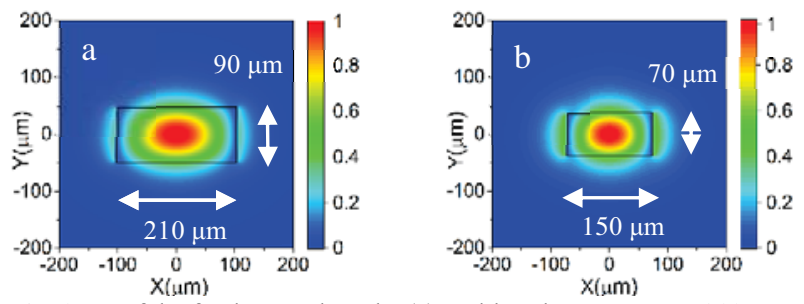

Fig. 1: $E_{\chi}$ of the fundamental mode: (a) multimode structure $\mathrm{w}=210 \mu \mathrm{m}$ $\mathrm{T}=90 \mu \mathrm{m}$ and (b) single mode structure $\mathrm{w}=150 \mu \mathrm{m} \mathrm{T}=70 \mu \mathrm{m}$
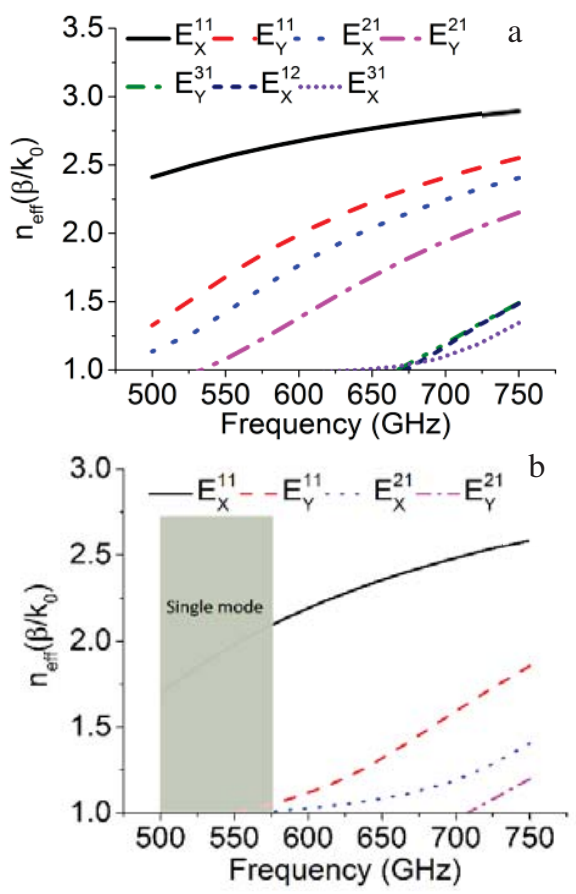

Fig. 2: Propagation constant: (a) multimode structure $\mathrm{w}=210 \mu \mathrm{m} \mathrm{T}=90$ $\mu \mathrm{m}$ and (b) single mode structure $\mathrm{w}=150 \mu \mathrm{m} \mathrm{T}=70 \mu \mathrm{m}$ 
To measure losses of this waveguide, structure with different physical length are fabricated and measured to finally extract the losses by cut-back method. Measurements have done using a free-space S-parameter extraction, with a vector network analyser in the 500-750 GHz frequency range. The measured losses are ultra-low $(\approx 0.2 \mathrm{~dB} / \mathrm{cm})$ which are much lower than previous similar suspended waveguide[2] and photonic crystal line defect waveguides[3].

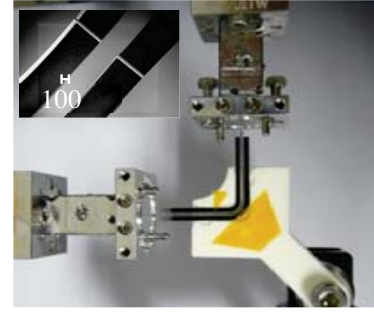

Fig. 3 Suspended Si waveguide on the VNA measurement setup; insert: microscopic image of this waveguide

\section{PHOTONIC CRYSTAL HIGH Q CAVITY}

We benefited from these very low losses of our waveguide to create an integrated high Q optical cavity on the top of it. Circular periodic etching in the silicon ridge are created. This process allows to have a $1 \mathrm{D}$ photonic crystal where the guided mode is splitted into two air and dielectric mode with a large band gap in between where no mode is allowed to propagate[4]. Creating a defect in the etching periodicity of the crystal, or the etching radius leads to have a defect localized mode, inside the bandgap and an optical cavity with defined resonance frequency in formed. In our design we chose to create an air defect mode and that to correspond with our necessity to confine the electric filed in the air region for sensing purpose. So we create a variation of the etching period, by increasing it from $106 \mu \mathrm{m}$ to $121 \mu \mathrm{m}$, in order to pull down the air mode. A parabolic variation is used in order to reduce the mismatch between the waveguide and cavity modes[5]. The etching radius is fixed at $29 \mu \mathrm{m}$, and the number of holes is set to 25 . The radius of the hole defines the resonance frequency, so for different cavities we simulated different etching radius, and this allow to control the resonance frequency by only defining the etching radius. The simulated results are represented in figure 6 , where 3 resonance frequencies are shown for 3 different cavities with different etching radius and same lattice constant variation.

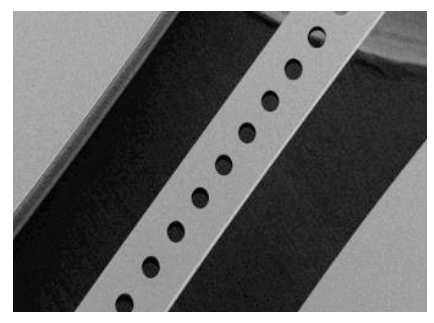

Fig. 5:Microscopic photo of photonic crystal cavity

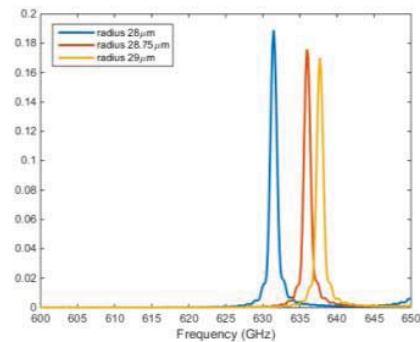

Fig. 6: Resonance frequencies of three different cavities with different etching radius $28,28.75$ and $29 \mu \mathrm{m}$
In the simulation material losses are not taken into account, so high Q factor are simulated up to 66900 .
The cavity with etching radius $29 \mu \mathrm{m}$ is fabricated and tested. The same measurement setup used to extract the waveguide losses is also used to characterize the cavity. The measured etching radius was slightly larger around $29.4 \mu \mathrm{m}$, so new simulation run are done in order to match with the experimental size. In order to understand the effect of material losses on the quality factor of the cavity $0.2 \mathrm{~dB} / \mathrm{cm}$ of losses are added to the simulation and the quality factor of this cavity is reduced to 9200.

On the figure 7 the measured resonance frequency is represented. $S_{21}$ and $S_{11}$ parameters shows the transmission peak and the reflection dip, that correspond to the same simulated resonance frequency at $640.2 \mathrm{GHz}$. Taking the FWHM of the transmission peak at $\mathrm{S}_{21 \text { max }}-3 \mathrm{~dB}$, allow to extract the Quality factor of the resonant mode $Q=\frac{F_{\text {Resonance }}}{F W H M}=\frac{640.2}{0.07}$ $=9146$, which correspond to the simulated quality factor with material loss of $0.2 \mathrm{~dB} / \mathrm{cm}$.

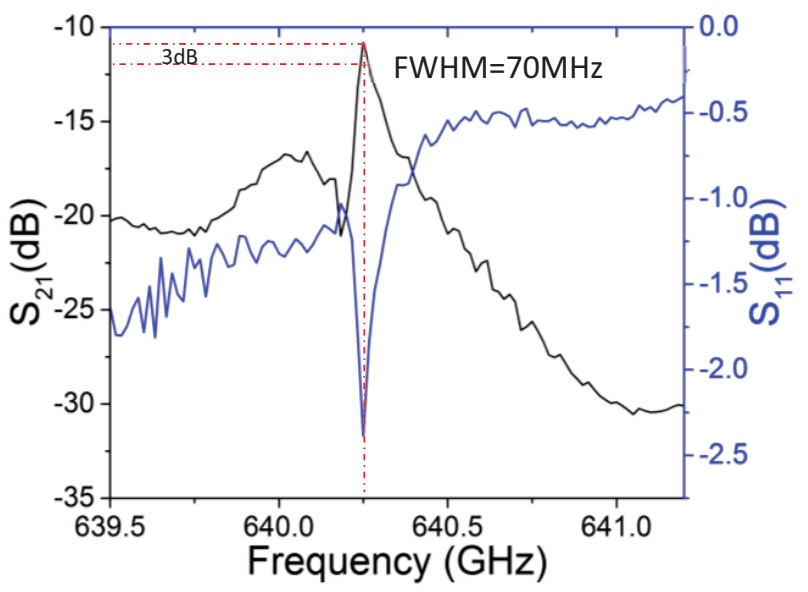

Fig. 7: Measured $S_{21}$ and $S_{11}$ of the resonant frequency

\section{CONCLUSION}

Finally, in this work we showed experimental results of a very high Q optical cavity and very low loss silicon suspended waveguide at Terharetz frequencies for the use in a photoacoustic gas sensor.

[1] P. Patimisco, G. Scamarcio, F. K. Tittel, and V. Spagnolo, "Quartz-Enhanced Photoacoustic Spectroscopy: A Review," Sensors, vol. 14, no. 4, pp. 6165-6206, Apr. 2014.

[2] N. Ranjkesh, M. Basha, A. Taeb, and S. Safavi-Naeini, "Silicon-on-Glass Dielectric Waveguide-Part II: For THz Applications," IEEE Trans. Terahertz Sci. Technol., vol. 5, no. 2, pp. 280-287, Mar. 2015.

[3] H. Amarloo and S. Safavi-Naeini, "Terahertz Line Defect Waveguide Based on Silicon-on-Glass Technology," IEEE Trans. Terahertz Sci. Technol., vol. 7, no. 4, pp. 433-439, Jul. 2017.

[4] J. D. Jannopoulos, Photonic crystal Molding the flow of the light. .

[5] W. Xie et al., "High-Q Photonic Crystal Nanocavities on 300 mm SOI Substrate Fabricated With 193 nm Immersion Lithography," J. Light. Technol., vol. 32, no. 8, pp. 1457-1462, Apr. 2014. 